\title{
Epidemiology of Epizootic Lymphangitis Among Carthorses in Ethiopia
}

\author{
Musse G. Abdela ${ }^{1}$, Sori Teshale ${ }^{2 *}$, Mesfin M. Gobena ${ }^{3}$, Aboma Zewde ${ }^{4}$, Hawi Jaleta ${ }^{5}$, \\ Balako Gumi ${ }^{1}$ and Gobena Ameni ${ }^{1,6 *}$ \\ ${ }^{1}$ Aklilu Lemma Institute of Pathobiology, Addis Ababa University, Addis Ababa, Ethiopia, ${ }^{2}$ Department of Clinical Studies, \\ College of Veterinary Medicine and Agriculture, Addis Ababa University, Bishoftu, Ethiopia, ${ }^{3}$ Department of Animal Sciences, \\ University of Florida, Gainesville, FL, United States, ${ }^{4}$ The Ethiopian Public Health Institute (EPHI), Addis Ketema Sub-city, \\ Addis Ababa, Ethiopia, ${ }^{5}$ School of Veterinary Medicine, College of Health Science, Wollega University, Nekemte, Ethiopia, \\ ${ }^{6}$ Department of Veterinary Medicine, College of Food and Agriculture, United Arab Emirates University, Al Ain, United Arab \\ Emirates
}

OPEN ACCESS

Edited by:

Francois Louis Roger

CIRAD, Vietnam

Reviewed by:

Helene Guis,

Institut National de la Recherche

Agronomique (INRA), France

Annelize Jonker,

University of Pretoria, South Africa

${ }^{*}$ Correspondence:

Sori Teshale

teshalesori2002@yahoo.com

teshale.sori@aau.edu.et

Gobena Ameni

gobena.ameni@aau.edu.et;

gobena.ameni@uaeu.ac.ae

Specialty section: This article was submitted to

Veterinary Epidemiology and Economics,

a section of the journal

Frontiers in Veterinary Science

Received: 23 August 2021

Accepted: 20 October 2021

Published: 10 December 2021

Citation:

Abdela MG, Teshale S, Gobena MM

Zewde A, Jaleta H, Gumi B and Ameni G (2021) Epidemiology of Epizootic Lymphangitis Among

Carthorses in Ethiopia.

Front. Vet. Sci. 8:762937.

doi: 10.3389/fvets.2021.762937
Epizootic lymphangitis caused by Histoplasma capsulatum variety farciminosum is a debilitating disease incurring considerable economic losses and affecting the welfare of carthorses. Understanding of its epidemiology is important for devising effective prevention and control measures. A cross-sectional study was conducted on 4,162 carthorses in 17 towns in Ethiopia between October 2018 and June 2019. Clinical and microscopic examinations, fungal culturing, and polymerase chain reaction were used to undertake this study. The overall prevalence of epizootic lymphangitis was 16.67\% (95\% Cl: 15.55-17.84) in carthorses. Epizootic lymphangitis was detected in carthorses found in 16 of the 17 towns included in the study. The highest prevalence was recorded at Kombolcha Town (33.33; 95\% Cl: 27.54-39.52) whereas the lowest was recorded at Debre Birhan Town $(0.00 ; 95 \% \mathrm{Cl}$ : 0.00-1.27). The results of univariable firth logistic regression analysis showed that the difference between the prevalence of Kombolcha and the prevalences of all the other towns except Holota and Shashemene were statistically significant. Statistically significantly lower prevalence was observed in other towns. Classification of the cases into different clinical forms showed that 87.18, 4.33, and $0.58 \%$ were cutaneous, ocular, and respiratory forms respectively, while the remaining $7.93 \%$ (55/694; 95\% Cl: 6.03-10.19) were classified as mixed form. In terms of the severity of the disease, 28.67, 60.52, and $0.81 \%$ were mild, moderate, and severe cases, respectively. The majority of the lesions (43.95\%) were observed in the skin followed by forelimbs (14.55\%) and neck region (14.27\%). Higher mean annual temperature, lower annual rainfall, and higher humidity of the study towns were statistically significantly associated with an increased risk of epizootic lymphangitis. In conclusion this study revealed widespread occurrence of epizootic lymphangitis in carthorses yet a heterogeneous prevalence between towns. The veterinary and livestock authorities should take this into account while devising disease control.

Keywords: epizootic lymphangitis, Histoplasma capsulatum variety farciminosum, epidemiology, carthorses, Ethiopia 


\section{INTRODUCTION}

In Ethiopia, horses provide a multitude of services to both rural and urban communities, which are crucial for their livelihood. Horses still serve in several areas as the only available and affordable means of public and goods transportation (1). In certain parts horses provide draft power for preparation of croplands $(1,2)$. Despite their immense services, horses often suffer from a number of infectious diseases having considerable impacts on their welfare and livelihood of their owners. Epizootic lymphangitis is one of the infectious diseases posing huge socioeconomic and welfare concerns on horses, specially carthorses. It is a contagious, chronic, debilitating disease caused by a thermally dimorphic fungus Histoplasma capsulatum variety farciminosum which occurs as a yeast form in host tissues and as a mycelial saprophytic form in the environment (3).

Although epizootic lymphangitis is endemic in several countries causing significant economic and welfare issues, it is an OIE non-listed disease. Based on the route of infection, epizootic lymphangitis can occur as cutaneous, respiratory, ocular, and asymptomatic forms (4). Cases involving a combination of all forms occur rarely. Transmission of epizootic lymphangitis mostly occurs through contacts with infectious cases, but the role of inanimate objects (harness and other implements) and fly vectors via broken skin cannot be ruled out $(4,5)$.

Epizootic lymphangitis was widespread in Europe during the late nineteenth and twentieth centuries and was eradicated through regular surveillance and slaughter programs (6). Currently it is common in many African countries, the Middle East, Russia, and Asia with tropical and subtropical climates $(2,5,7,8)$.

In Ethiopia, studies showed that it is a widespread disease affecting $18.8-26.2 \%$ of carthorses $(7,9)$ and $21 \%$ of cart mules (2). Previous surveys conducted a decade ago reported no cases of epizootic lymphangitis in areas characterized by cool temperature and higher elevation $(2,7,9)$. Yet recent personal observations indicate that epizootic lymphangitis can be observed in carthorses in some towns with cool temperature and high-altitude such as Dessie (northern Ethiopia), Holeta, and Sebeta (central Ethiopia). To better characterize the situation in these areas and to update and identify risk factors associated with epizootic lymphangitis distribution in Ethiopia, we investigated the epizootic lymphangitis prevalence in carthorses in 17 selected towns of Ethiopia. This will help design tailored intervention strategies aimed at reducing its occurrence.

\section{MATERIALS AND METHODS}

\section{Study Area}

The study was conducted in 17 towns selected from Amhara and Oromia National Regional States of Ethiopia (Figure 1). Amhara and Oromia Regional States are the two largest states in terms of area coverage, human population, and natural resources including livestock. Together Oromia and Amhara regions have a total of $1,572,532$ horses which is $78.6 \%$ of the total horse population of the country (6). The climatic and ecological features these regions are very conducive for agriculture and livestock production. These two regions were, therefore, selected purposively. The remaining regional states are either predominantly pastoral or situated in the tse tse fly belt where horses are rare. The towns were selected purposively based on the number of carthorses present, the climatic conditions, and their accessibility to transportation to avoid spoilage of samples. The mean annual temperature of the study towns ranges from 21.1 to $31.2^{\circ} \mathrm{C}$; the mean annual rainfall ranges from 83.8 to $167.5 \mathrm{~mm}$; the mean annual humidity ranges from 56 to $83 \%$, and the average altitude ranges from 1,438 to $3,206 \mathrm{~m}$ above sea level (Table 1). The towns are featured by fast urbanization where the demand for transportation is escalating. To this end the number carthorses providing transportation services is increasing as well.

\section{Study Population and Design}

A cross-sectional study was conducted from October 2018 to May 2020 to investigate the epidemiology of epizootic lymphangitis in carthorses in Ethiopia. The study population comprises carthorses found in the selected towns. The total number of carthorses in each town was obtained from the municipalities of each town as it is mandatory for owners to register for issues related to administration and tax. There are 4-5 carthorse stations in each town and these stations were used as sampling sites. The carthorses and their drivers wait for customers at the stations where they pick passengers or goods. There are a total of 4,380 registered carthorses in the 17 towns. Each cart owner has two horses that pull the same cart. One of the horses is used during the morning hours whereas the other one is used in the afternoon while the cart remains the same. For this reason, each carthorse station was visited twice a day, in the morning and in the afternoon, in order to examine and sample all horses. Horses are used singly to pull carts and no pairing was observed. The horses are stabled in the same enclosure at night. During this study a total of 4,162 carthorses were sampled (nearly $95 \%$ of the total carthorses in the selected towns). The remaining 5\% were not included due to unwillingness of the owners.

\section{Clinical Examination of Horses}

All carthorses found in the stations were clinically examined for the presence of any lesions suggestive of epizootic lymphangitis by inspection and palpation, particularly for the presence of nodules and/or ulcers. Great emphasis was given to nostrils and eyes, the skin, and lymphatics during physical examination of the horses. Based on the clinical examination the horses were classified as healthy (no detectable lesion), clinically positive cases (having mild, moderate, or severe lesion scores) based on the the grading system described by Mideksa et al. (10), and confirmed cases (horses with a positive smear). The owners and drivers of each carthorse were asked if they had seen any visible epizootic lymphangitis lesions on their carthorses.

\section{Sample Collection}

Samples were collected from all horses suspected to have lesions of epizootic lymphangitis. Pus samples were aspirated aseptically by sterile needles and syringes from un-ruptured nodules. The nodules were washed using water and soap, shaved 

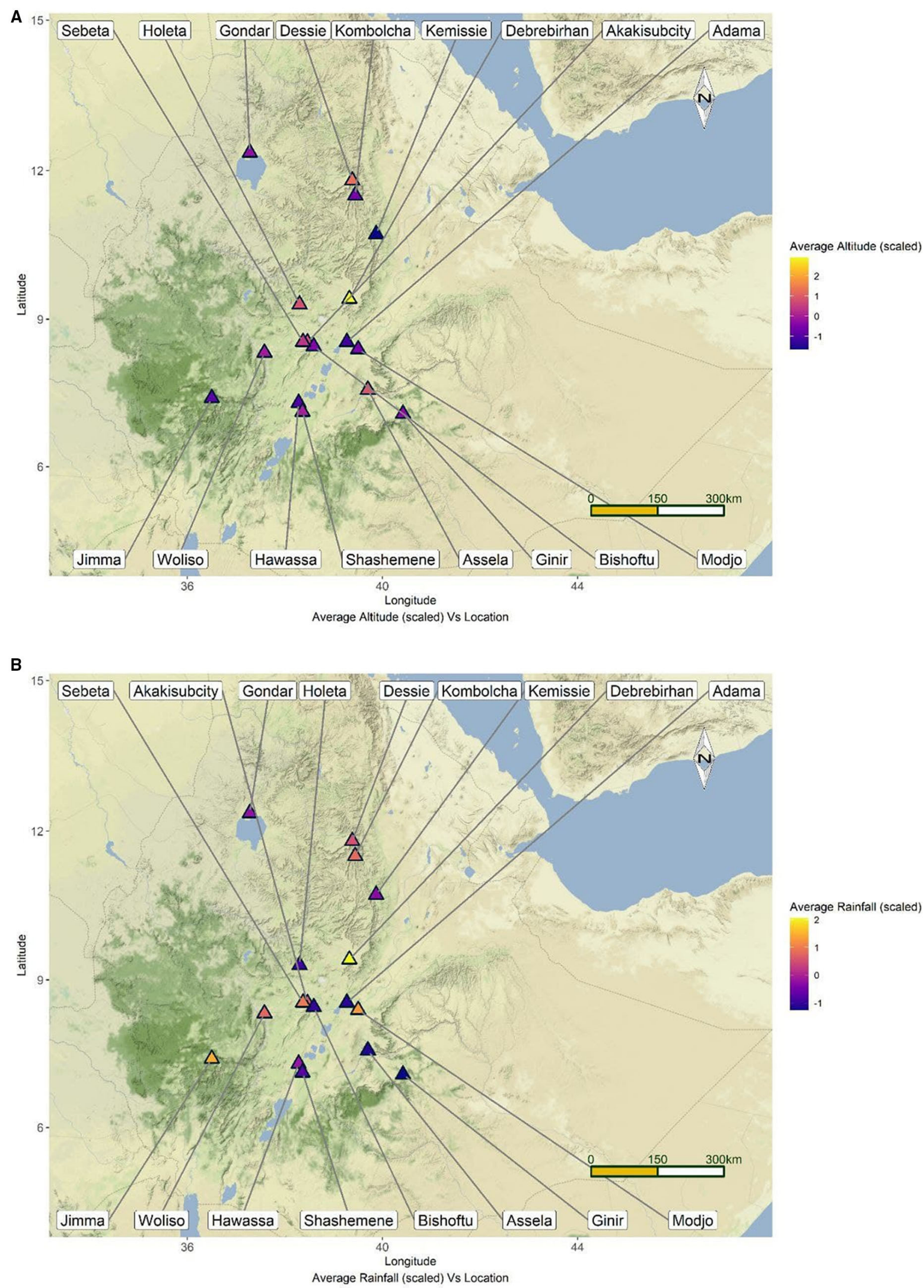

FIGURE 1 | continued 


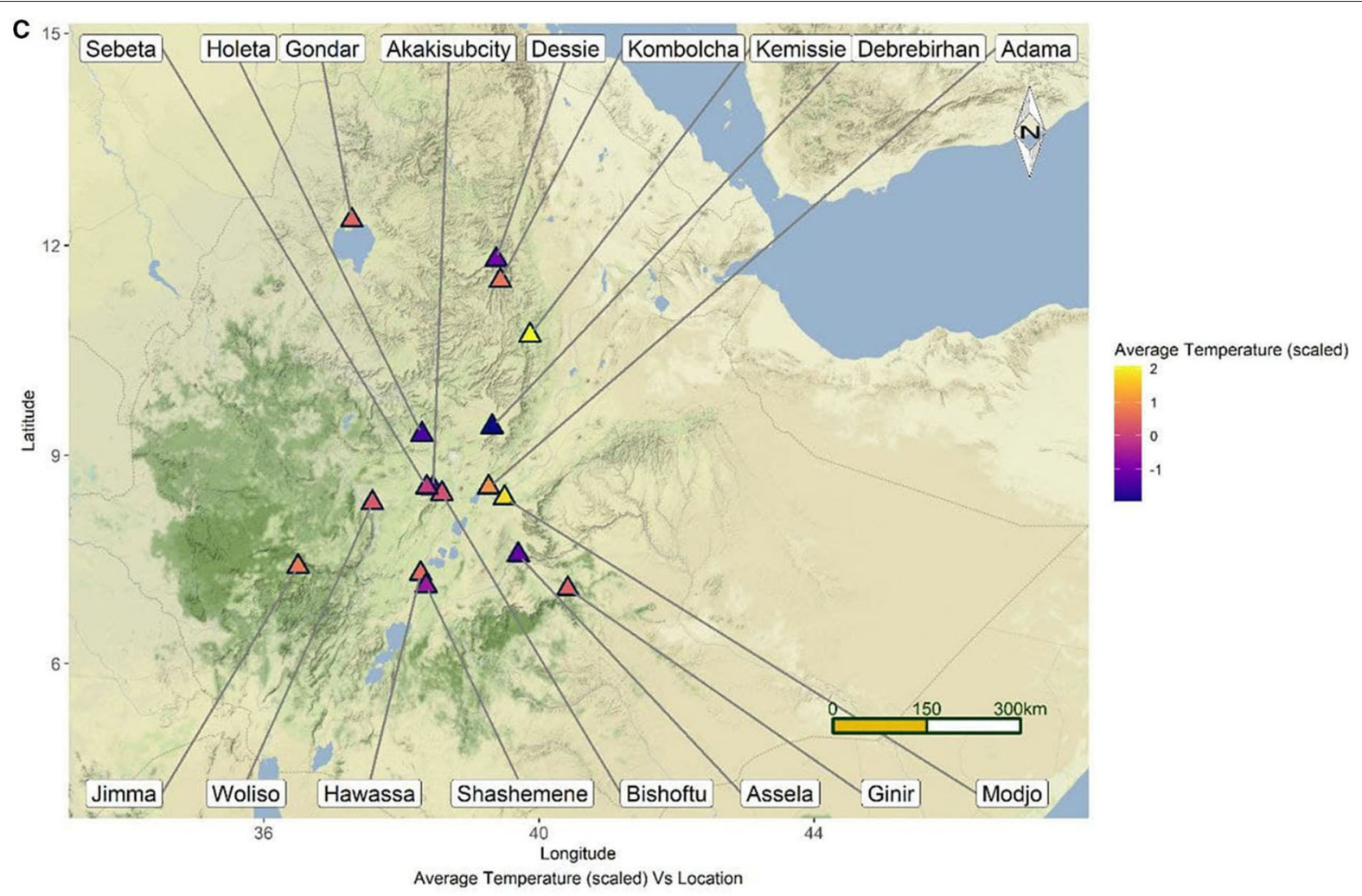

D

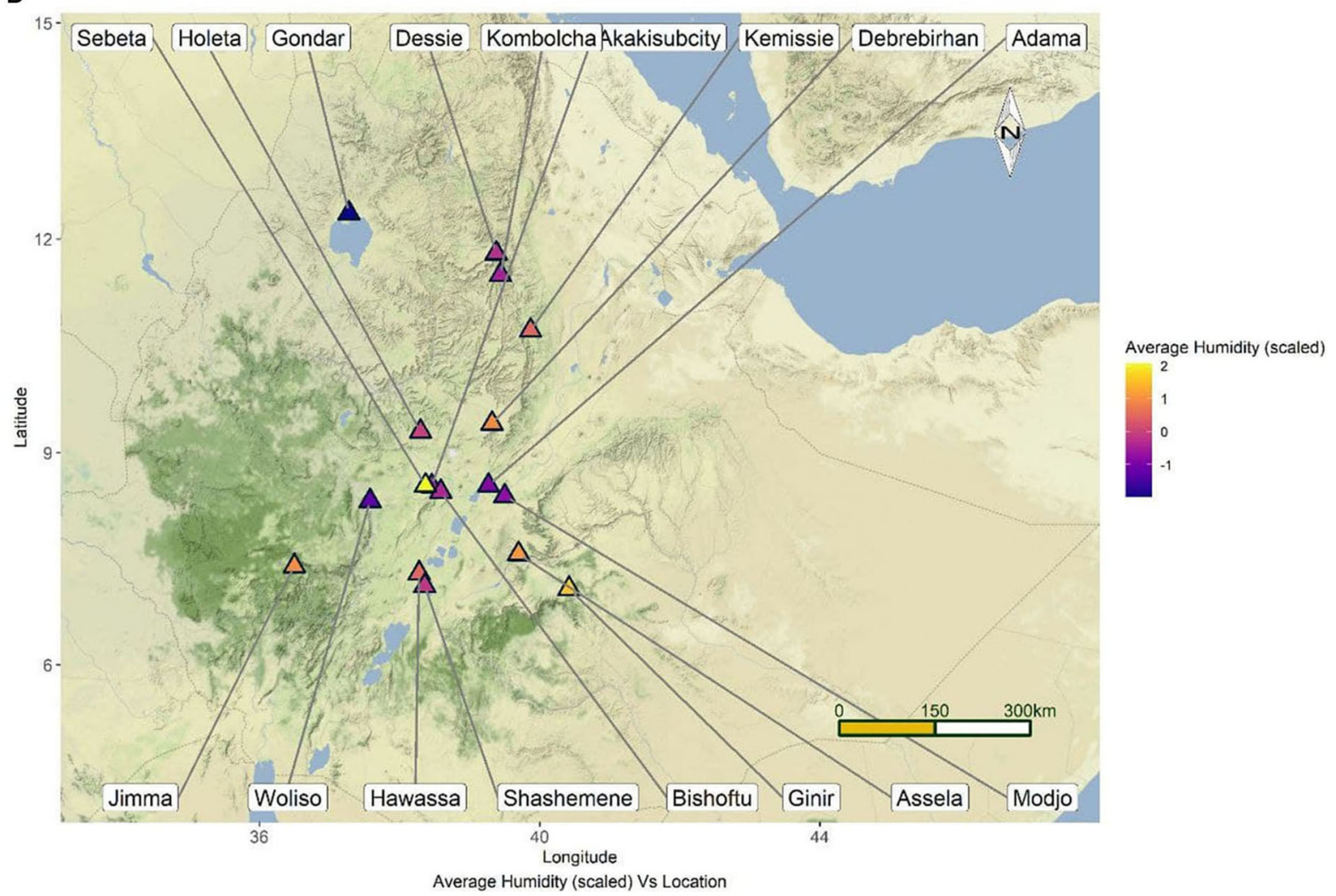

FIGURE 1 | Map of Ethiopia depicting the locations of the study towns along with their mean altitude (A), rainfall (B), temperature (C), and humidity (D). 
TABLE 1 | The mean annual temperature, rainfall, humidity and average altitude of the study towns.

\begin{tabular}{lcccc}
\hline Town & Temperature ${ }^{\circ} \mathbf{C}$ ) & Rainfall $(\mathbf{m m})$ & Humidity $(\%)$ & Altitude $(\mathbf{m}$ asl) \\
\hline Adama & 28.5 & 88.0 & 59 & 1,622 \\
Akaki & 23.0 & 131.8 & 62 & 2,354 \\
Asella & 23.1 & 86.5 & 75 & 2,413 \\
Bishoftu & 26.5 & 90.0 & 63 & 1,900 \\
Debrebirhan & 21.1 & 167.5 & 74 & 3,206 \\
Dessie & 23.5 & 128.7 & 64 & 2,553 \\
Gindhir & 27.1 & 83.8 & 79 & 1,941 \\
Gondar & 27.2 & 110.0 & 50 & 1,973 \\
Hawassa & 27.3 & 111.0 & 70 & 1,694 \\
Holota & 22.4 & 93.0 & 66 & 2,391 \\
Jimma & 27.8 & 152.4 & 74 & 1,718 \\
Kemisse & 31.2 & 108.0 & 70 & 1,438 \\
Kombolcha & 27.7 & 135.9 & 62 & 1,857 \\
Modjo & 30.5 & 147.2 & 60 & 1,870 \\
Sebeta & 25.7 & 140.0 & 83 & 2,220 \\
Shashemene & 24.5 & 97.0 & 65 & 2,080 \\
Weliso & 26.8 & 134.8 & 56 & 2,058 \\
\hline & & & & \\
\hline
\end{tabular}

with sterile scalpel blade, and disinfected with $70 \%$ alcohol. For nodular lesions observed on skin and lymphatics, sterile syringe and needles were used to aspirate the pus samples. Sterile $10 \mathrm{~cm}$ long swab was used to collect pus samples from the ocular and respiratory forms of epizootic lymphangitis. The samples collected were immediately transferred into a sterile universal bottle containing saline solution and kept cool using an icebox. The collection was done after obtaining permission from owners of the carthorses under the supervision of local administration. The bottles were labeled and transported to Veterinary Microbiology Laboratory, Akililu Lemma Institute of Pathobiology, Addis Ababa University for laboratory examination. The samples were stored refrigerated at $4^{\circ} \mathrm{C}$ and processed within $24-48 \mathrm{~h}$ of submission. When sample processing was not possible within $48 \mathrm{~h}$, they were frozen at $-80^{\circ} \mathrm{C}$.

Geo-referenced data were collected during sample collection from each town using Android version 4.4 phones, which captured the altitudes of the towns and the Geographical Positioning System device was used to identify the latitude and longitude of the towns. Climatic data such as the mean annual temperature, the mean annual rainfall, and the mean annual humidity of each town were obtained from National Meteorological Agency of Ethiopia.

\section{Microscopic Examination}

For microscopic examination smear was prepared from the pus and swab samples on glass slide in the field prior to transfer into sterile saline, fixed with methanol, and kept on the slide box. The smears were stained with Wright-Giemsa stain and examined under microscope for the typical yeast form of Histoplasma capsulatum variety farciminosum which appears as ovoid to globose structures occurring singly or in group either inside cells or in extracellular space (4). The horses with positive smears were considered as confirmed positives and were used to compute prevalence of epizootic lymphangitis in this study.

\section{Isolation of Histoplasma capsulatum Variety farciminosum}

Primary isolation of Histoplasma capsulatum variety farciminosum was done on Brain Heart Infusion Aagar (BHIA) with 5\% horse blood and $0.005 \%$ chloramphenicol. Chloramphenicol $(0.5 \mathrm{~g} / \mathrm{L})$ was added to the media to avoid the growth of bacterial contaminants. The inoculated media were incubated at $26^{\circ} \mathrm{C}$ and $5 \% \mathrm{CO}_{2}$ for about 8-12 weeks (4). The growth of the mycelial form of Histoplasma capsulatum variety farciminosum was evident when dry, gray-white, granular wrinkled colonies were observed. Typical colonies were collected and stained with Gram's stain for demonstration of the morphologic features of Histoplasma capsulatum variety farciminosum. From the primary cultures, typical colonies were further sub-cultured onto Sabouraud dextrose agar (SDA, Oxoid) enriched with $2.5 \%$ glycerol and $0.005 \%$ chloramphenicol. The isolates with typical colony appearance and morphologic features of Histoplasma capsulatum variety farciminosum were subjected to nested polymerase chain reaction (PCR) for confirmation of their identity.

\section{Molecular Identification of Histoplasma capsulatum Variety farciminosum \\ Extraction of DNA}

The modified sodium dodecyl sulfate (SDS)-cetyltrimethylammonium bromide (CTAB)-chloroform-isoamyl alcohol method was used for the extraction of DNA (11). Briefly, $200 \mathrm{mg}$ of mycelial growth was taken and transferred to $2 \mathrm{~mL}$ Eppendorf tube. Five hundred microliter of SDS-CTABchloroform-isoamyl alcohol extraction buffer $(250 \mathrm{mM}$ Tris- $\mathrm{HCl}$ [pH 8.0], $20 \mathrm{~m}$ MEDTA [pH 8.0], $200 \mathrm{M} \mathrm{NaCl}, 10 \%$ CTAB, and $0.15 \%$ SDS) was added and vortexed. The mixture was boiled at $50^{\circ} \mathrm{C}$ for $10 \mathrm{mins}$ and centrifuged at $10,000 \mathrm{~g}$ for $10 \mathrm{mins}$. The supernatant was aspirated carefully and mixed with one volume of chloroform: isoamyl alcohol (23:2) for $1 \mathrm{~min}$ and centrifuged at $10,000 \mathrm{~g}$ for 5 mins. The aqueous phase was collected and mixed with one volume of ice-cold isopropanol, and the tubes were turned upside down for $1 \mathrm{~min}$ to precipitate the DNA. The tubes were centrifuged at $10,000 \mathrm{~g}$ for $2 \mathrm{mins}$ to recover the pellet and washed with $500 \mathrm{~mL}$ of absolute ethanol and then centrifuged at 10,000 $\mathrm{g}$ for $1 \mathrm{~min}$. The pellet was air dried, and the DNA was resuspended in $200 \mathrm{~mL}$ deionized or TE buffer. The DNA was either used for amplification or stored at $-20^{\circ} \mathrm{C}$ until analyzed.

\section{Amplification and Visualization}

A nested PCR amplifying about 514 bp of DNA was used as described by Jiang et al. (12) and Scantlebury et al. (13) using primers designated P3, 2R8, F5, and 2R5 supplied by Eurofins Genetics, Germany. DNA of $H$. capsulatum var. farciminosum reference strain CBS 539.84 was used as positive control whereas extracts of Saccharomyces cerevisiae DNA were used as negative control. Each PCR reaction mixture contained $50 \mathrm{ng} / \mathrm{mL}$ of 
template DNA and 10 pmol of PCR primers P3 and 2R8 added to BioMix red (Bioline Reagents Limited, UK) in a $25 \mathrm{~mL}$ reaction volume, as follows: $12 \mathrm{~mL}$ BioMix red, $2 \mathrm{~mL}$ forward primer, and $2 \mathrm{~mL}$ reverse primer, $8 \mathrm{~mL}$ water, and $1 \mathrm{~mL}$ of DNA template $(50 \mathrm{ng} / \mu \mathrm{L})$. The first round of PCR was run using the P3 (forward primer: 50-CGGAAGGATCATTACCACGCC G-30) and 2R8 (reverse primer: 50-CAGCGGGTATCCCTACCT GATC-30) in the thermal cycler (Eppendorf Master cycler) with denaturation at $94^{\circ} \mathrm{C}$ for 10 mins followed by 35 cycles of the succeeding steps of denaturation at $94^{\circ} \mathrm{C}$ for $1 \mathrm{~min}$, annealing at $49^{\circ} \mathrm{C}$ for $1 \mathrm{~min}$ and extension at $72^{\circ} \mathrm{C}$ for $1 \mathrm{~min}$ and a final extension period of $72^{\circ} \mathrm{C}$ of 7 mins. A 1 -in-10 (v/v) dilution of the product from the first reaction was added to fresh master mix and amplified using forward primer: F5 (50-CTACCCGGCCAC CCTTGTCTAC-30) and reverse primer: 2R5 (50- CCTACCTGA TCCAGTCAACC-30). The reaction cycles for the second round of PCR were the same as the first round, except that the annealing temperature was raised to $55^{\circ} \mathrm{C}$ for $1 \mathrm{~min}$. The PCR products were visualized by gel electrophoresis using $2 \%$ agarose (Sigma Chemical Co, St. Louis, MO) dissolved in Tris-borate-EDTA buffer (0.1 M Tris, 0.09 M boric acid, and 0.001 M EDTA [pH $8.4]$ ), allowing it to solidify and finally staining with ethidium bromide ( $3 \mathrm{~mL}$ per $100 \mathrm{~mL}$ agarose). The electrophoresis was conducted at $90 \mathrm{~V}$ for 50 mins by mixing $5 \mathrm{~mL}$ of each PCR product with $1 \mathrm{~mL}$ of loading dye in each well. The bands were visualized with a UV transilluminator.

\section{Data Analysis}

Data were checked, coded, and entered into Microsoft Excel 2010 (Microsoft Corp., Redmond, USA) and analyzed using Stata version 14 (StataCorp, 4905 Lakeway Drive, College Station, Texas 77845 USA). Prevalence was calculated by dividing the number of smear positive carthorses by a total number of carthorses examined then multiplied by 100 and $95 \%$ CI was constructed. Multivariable logistic regression was used compute associations between the prevalence of epizootic lymphangitis and climatic factors such as altitude, annual temperature, annual humidity, and annual rainfall of the study towns (National Meteorology Service). The association between the prevalence and the study towns was assessed by univariable firth logistic regression analysis. A difference was taken as significant at a $p$-value $\leq 0.05$.

\section{RESULTS}

\section{Prevalence of Epizootic Lymphangitis}

A total of 4,380 carthorses were encountered, of which 4,162 examined clinically for epizootic lymphangitis. Overall 577 horses had showed clinical signs of which 694 gave smear positive results yielding a prevalence of $16.67 \%$ (95\% CI: $15.55-$ 17.84). Epizootic lymphangitis was detected in carthorses found in 16 of the 17 towns included in the study. The highest prevalence was recorded at Kombolcha Town (33.33; 95\% CI: 27.54-39.52) followed by Shashemene Town (24.25; 95\% CI: 20.13-28.76) whereas the lowest was recorded at Debre Birhan Town which was $0.00 \%$ (95\% CI: $0.00-1.27)$. The results showing the prevalence of epizootic lymphangitis per town is presented
TABLE 2 | Prevalence of Epizootic Lymphangitis in carthorses per town.

\begin{tabular}{lcccc}
\hline Town & No examined & No positive & Prevalence & 95 \% Cl \\
\hline Adama & 150 & 15 & 10.00 & $5.71-15.96$ \\
Akaki & 80 & 12 & 15.00 & $7.99-24.74$ \\
Assela & 360 & 43 & 11.94 & $8.78-15.75$ \\
Bishoftu & 35 & 75 & 21.43 & $17.25-26.10$ \\
Debrebirhan & 234 & 0 & 0.00 & $0.00-1.27$ \\
Dessie & 150 & 6 & 4.00 & $1.48-8.51$ \\
Gindhir & 120 & 18 & 15.00 & $9.14-22.67$ \\
Gondar & 384 & 34 & 8.85 & $6.21-12.15$ \\
Hawassa & 410 & 73 & 17.81 & $14.23-21.86$ \\
Holota & 307 & 91 & 22.64 & $24.59-35.09$ \\
Jimma & 302 & 59 & 19.54 & $15.22-24.46$ \\
Kemisse & 112 & 18 & 16.07 & $9.81-24.21$ \\
Kombolcha & 252 & 84 & 33.33 & $27.54-39.52$ \\
Mojo & 200 & 8 & 4.00 & $1.75-7.73$ \\
Sebeta & 150 & 31 & 20.67 & $14.49-28.03$ \\
Shashemene & 400 & 97 & 24.25 & $20.13-28.76$ \\
Weliso & 201 & 30 & 14.93 & $10.31-20.62$ \\
Total & $\mathbf{4 , 1 6 2}$ & $\mathbf{6 9 4}$ & $\mathbf{1 6 . 6 7}$ & $\mathbf{1 5 . 5 5 - 1 7 . 8 4}$ \\
\hline
\end{tabular}

TABLE 3 | Results of firth logistic regression analysis comparing the prevalence of Epizootic Lymphangitis among the towns studied.

\begin{tabular}{|c|c|c|c|c|c|}
\hline Location & OR & SE & $\mathbf{Z}$ & $P$-value & $95 \% \mathrm{Cl}$ \\
\hline Adama & 0.23 & 0.07 & -4.95 & 0.000 & $0.13-0.41$ \\
\hline Akaki & 0.36 & 0.12 & -3.03 & 0.002 & $0.19-0.69$ \\
\hline Assela & 0.27 & 0.06 & -0.62 & 0.000 & $0.18-0.41$ \\
\hline Bishoftu & 0.54 & 0.10 & -3.28 & 0.001 & $0.38-0.78$ \\
\hline Debrebirhan & 0.01 & 0.01 & -3.84 & 0.000 & $0.001-0.69$ \\
\hline Dessie & 0.1 & 0.04 & -5.72 & 0.000 & $0.04-0.20$ \\
\hline Gindhir & 0.36 & 0.10 & -3.60 & 0.000 & $0.21-0.63$ \\
\hline Gondar & 0.19 & 0.04 & -7.33 & 0.000 & $0.13-0.30$ \\
\hline Hawassa & 0.43 & 0.08 & -4.53 & 0.000 & $0.30-0.62$ \\
\hline Holota & 0.84 & 0.15 & -0.97 & 0.33 & $0.59-1.19$ \\
\hline Jimma & 0.48 & 0.09 & -3.68 & 0.000 & $0.33-0.71$ \\
\hline Kemisse & 0.39 & 0.11 & -3.30 & 0.001 & $0.22-0.68$ \\
\hline Mojo & 0.09 & 0.03 & -6.49 & 0.000 & $0.04-0.18$ \\
\hline Sebeta & 0.52 & 0.13 & -2.70 & 0.007 & $0.33-0.84$ \\
\hline Shashemene & 0.94 & 1.12 & -0.55 & 0.11 & $0.50-1.01$ \\
\hline Weliso & 0.35 & 0.08 & -4.39 & 0.000 & $0.22-0.56$ \\
\hline Constant & 0.50 & 0.07 & -5.13 & 0.000 & $0.39-0.66$ \\
\hline
\end{tabular}

in Table 2. The results of univariable firth logistic regression analysis showed that the differences between the prevalence of Kombolcha and the prevalences of all the other towns except Holota and Shashemene were statistically significant (Table 3).

\section{Diagnosis of Epizootic Lymphangitis}

The results of microscopic examination of smears prepared from fresh pus samples and swab samples revealed the 


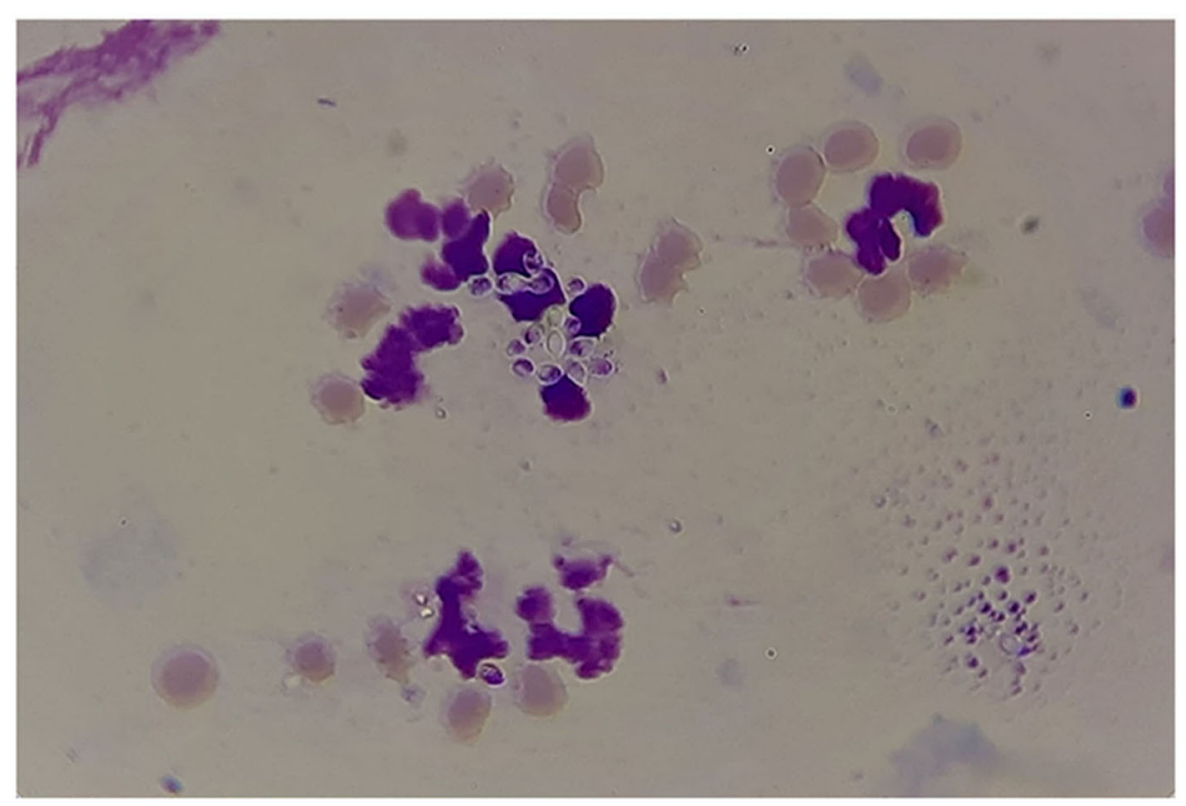

FIGURE 2 | Results of microscopic examination of morphological appearance of the yeast form of Histoplasma capsulatum variety farciminosum (arrows).

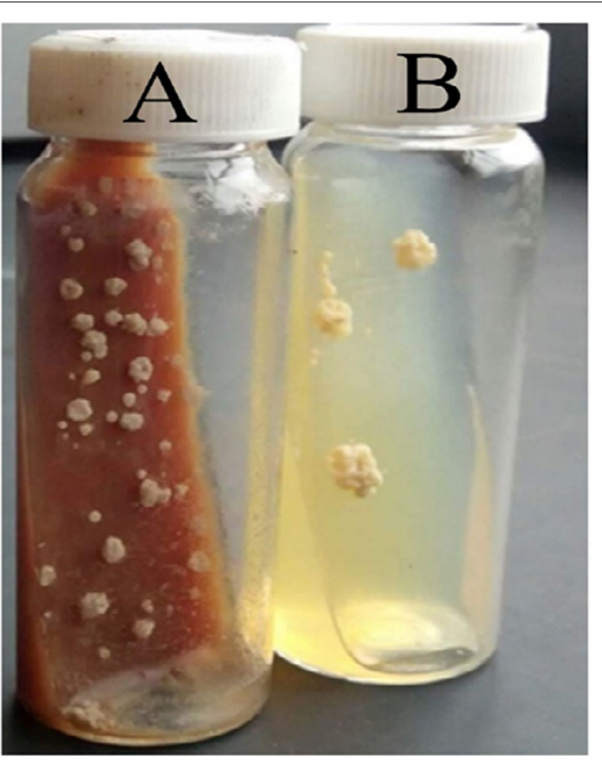

FIGURE 3 | Cultural appearances of Histoplasma capsulatum variety farciminosum. (A) 52 days old, primary culture of mycelial colonies on Brain Heart Infusion Aagar (with 5\% horse blood and 0.005\% chloramphenicol); (B) 48 days old sub-culture of the mycelial form on Sabouraud Dextrose Agar (with $2.5 \%$ glycerol and $0.005 \%$ chloramphenicol).

occurrence of double contorted yeast cells featured by grampositive, ovoid aggregates surrounded by a halo (Figure 2). Brown, dry, wrinkled colonies were cultured after 2 months of incubation at $26^{\circ} \mathrm{C}$ (Figures 3A,B). The colonies sub-cultured onto SDA supplemented with $2.5 \%$ glycerol revealed the growth of whitish to whitish-brown, dry, convoluted colonies, which revealed branching hyphae, chlamydospore, and macroconidia in Lactophenol cotton blue wet mounts examined under oil immersion.

Thirteen typical colonies from sub-culture were further tested by using conventional PCR using primers designated ITS1 and ITS4. The occurrence of DNA fragment of about $514 \mathrm{bp}$ revealing the involvement of Histoplasma capsulatum variety farciminosum was observed in those samples tested (Figure 4). Since the samples were collected from clinically affected horses the results of morphological, cultural, and molecular analysis were used to confirm the identity of Histoplasma capsulatum variety farciminosum.

Almost all of the carthorses with clinical signs showed one or more freely movable or firm nodules as well as ulcers on different parts of their bodies. Classification of the cases into different clinical forms showed that $87.18 \%$ (95\% CI: $84.46-$ 89.57), 4.33\% (95\% CI: 2.94-6.11), 58\% (4/694; 95\% CI: $0.16-$ 1.47) were cutaneous, ocular and respiratory forms, respectively while the remaining $7.93 \%$ (55/694; 95\% CI: 6.03-10.19) were classified as mixed form. In terms of the severity of the disease, 28.67\% (95\% CI: 25.34-32.19), 60.52\% (95\% CI: 56.77-64.18), and $0.81 \%$ (95\% CI: 8.59-13.36) were mild, moderate, and severe cases, respectively. The majority of the lesions (43.95\%) were observed in lymphatics along the limbs followed by forelimbs $(14.55 \%)$ and neck region (14.27\%). The distribution of the lesions is presented in Table 4.

\section{Effects of Climatic Factors and Altitude on Epizootic Lymphangitis}

The results of multivariable logistic regression analysis showed the mean annual temperature, average humidity, and mean annual rainfall of the study towns were statistically significantly 


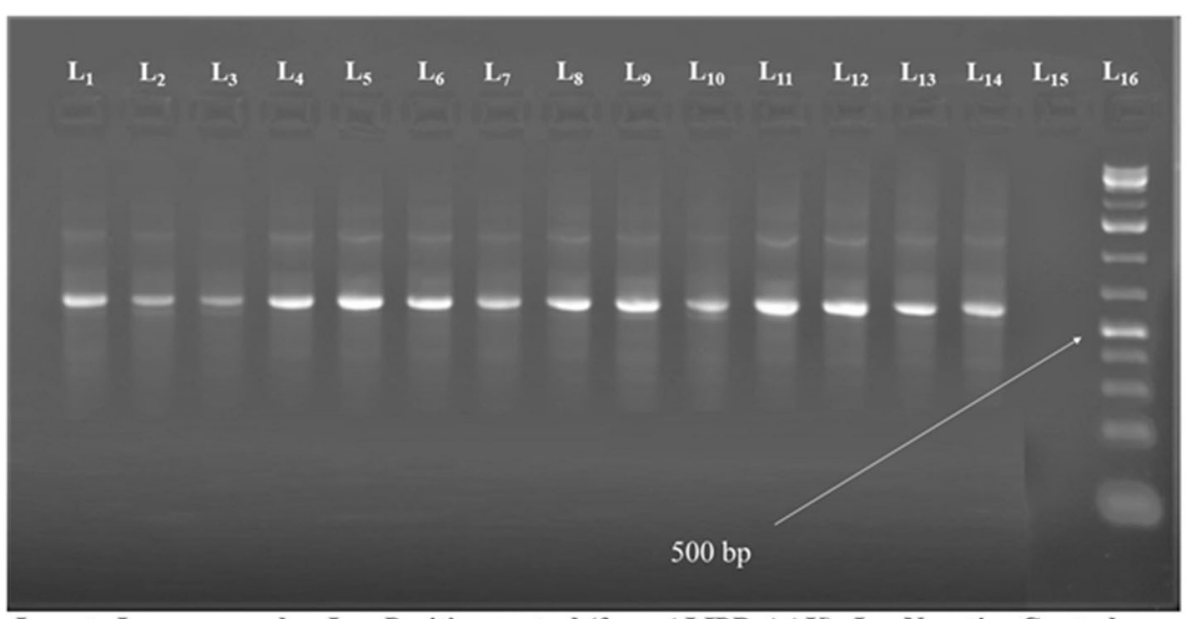

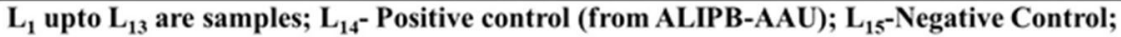
$\mathrm{L}_{16}$ - Molecular weight marker (1 Kb plus)

FIGURE 4 | The results of molecular diagnosis of Histoplasma capsulatum variety farciminosum using PCR.

TABLE 4 | Distribution of the lesions of Epizootic Lymphangitis in carthorses in the study areas.

\begin{tabular}{lccc}
\hline Body part & No horses & Percent & 95 \% Cl \\
\hline Lymphatic lines of the Limbs alone & 305 & 43.95 & $40.22-47.73$ \\
Neck region alone & 99 & 14.27 & $11.75-17.09$ \\
Neck and Forelimbs & 101 & 14.55 & $12.01-17.39$ \\
Perineum & 10 & 1.44 & $0.69-2.64$ \\
Sternal and ventral region & 55 & 7.93 & $6.03-10.19$ \\
Muzzle and Head & 35 & 5.04 & $3.54-6.94$ \\
Inguinal area & 25 & 3.60 & $2.35-5.27$ \\
All over the body & 64 & 9.22 & $7.17-11.62$
\end{tabular}

associated with occurrence of epizootic lymphangitis. As altitude and temperature were strongly correlated $\left(r^{2}=0.79\right)$, we built a model including only temperature, rainfall, and humidity, and then present the model with these variables. The odd of being infected with epizootic lymphangitis was 1.63 times higher in towns with mean annual temperature ranging from 27.1 to $31.2^{\circ} \mathrm{C}$ than those with lower temperature. Similarly the odd of infection was 2.54 times higher in towns that had average humidity in the range of $61-83 \%$ compared those with lower humidity. Towns receiving mean annual rainfall lower than $100 \mathrm{~mm}$ had higher odds of infection than those receiving higher rainfall. However, altitude was not associated with occurrence of epizootic lymphangitis (Table 5).

\section{DISCUSSION}

Horses remain invaluable animals serving the community in pack and saddle transport. However, their welfare and optimum service is hampered by diseases such as epizootic lymphangitis. In this study, the occurrence of epizootic lymphangitis was
TABLE 5 | The results of logistic regression analysis on the effects of climatic factors on the occurrence of epizootic lymphangitis in carthorses in Ethiopia.

\begin{tabular}{|c|c|c|c|c|c|c|}
\hline Variable & OR & SE & $\mathbf{Z}$ & $P$-value & $95 \% \mathrm{Cl}$ & \\
\hline \multicolumn{7}{|c|}{ Temperature $\left({ }^{\circ} \mathrm{C}\right)$} \\
\hline $21.1-27.0$ & Ref & & & & & \\
\hline $27.1-31.2$ & 1.63 & 0.17 & 4.65 & 0.000 & 1.33 & 2.01 \\
\hline \multicolumn{7}{|l|}{ Rainfall (mm) } \\
\hline 83.8-100 & Ref & & & & & Ref \\
\hline $101-167.5$ & 0.68 & 0.07 & -3.84 & 0.000 & 0.56 & 0.83 \\
\hline \multicolumn{7}{|l|}{ Humidity (\%) } \\
\hline 56-60 & Ref & & & & & \\
\hline $61-83$ & 2.54 & 0.39 & 5.97 & 0.000 & 1.87 & 3.44 \\
\hline Constant & 0.09 & 0.02 & -14.31 & 0.000 & 0.07 & 0.14 \\
\hline
\end{tabular}

The bold values show the occurrence statistically highly significant association.

investigated in carthorse in 17 towns of Ethiopia to estimate its prevalence and assess the effects of climatic factors on its occurrence. The results revealed that epizootic lymphangitis occurs in 16 of the 17 towns investigated with overall prevalence of $16.67 \%$. This has significant implication for the carthorse owners and the public, who use cart transportation. This observation is in agreement with previous report of Ameni (7) which reported a prevalence of $18.76 \%$ in 19,082 carthorses in 28 towns of Ethiopia. Although the sample size and area coverage are limited in our study the results confirm to the previous study (7) suggesting the widespread occurrence of epizootic lymphangitis in carthorses throughout Ethiopia. On the other hand the prevalence observed in this study is lower than the reports of Hadush et al. (14) from northern Ethiopia (44\%). Our observation is higher than the reports of Wilson (15) from Sudan (17-58 cases per year) and that of Abdullahi et al. (16) from Nigeria (5.6\%). In addition to the overall prevalence, the highest 
and lowest prevalence observed in this study were similar to those reported earlier by Ameni (7). However, variations in prevalence were observed in some of the towns included in the study. Previous studies reported high prevalence in 11 towns including Mojo, Jimma, Bishoftu (7), and Weliso (24.9\%) reported by Asfaw et al. (17) where low to moderate prevalence is recorded in this study. The lower prevalence observed in Mojo and Bishoftu in this study could be attributed to intervention made by the Society for Protection of Animals Abroad (SPANA) through provision of training and harnesses that minimize wounds to the horses. In contrast, higher prevalence was recorded at Kombolcha, Shashemene, and Holota towns, where either low or no cases of epizootic lymphangitis were reported by previous researchers (7).

Interestingly, in both this study and the previous ones a large number of cases of epizootic lymphangitis were recorded in towns receiving mean annual rainfall ranging from 80 to $410 \mathrm{~mm}$, suggesting the role of climatic factors on the survival and spread of the fungus. In this study mean annual temperature, mean annual rainfall, and humidity are statistically associated with the occurrence of epizootic lymphangitis. Those towns having higher average temperature $\left(27.1-31.2^{\circ} \mathrm{C}\right)$, average rainfall ranging from 83.8 to $100 \mathrm{~mm}$, and average humidity of $61-83 \%$ had higher odds of occurrence of epizootic lymphangitis in horses. Altitude was strongly correlated with temperature; towns located at lower altitudes exhibited higher temperatures and were significantly more at risk of epizootic lymphangitis. The significant association between climatic factors and the risk of epizootic lymphangitis could be due to the survival of the mycelial stage of Histoplasma capsulatum variety farciminosum in the environment and on its transmission among horses. In agreement with our observation other authors documented that temperature up $29^{\circ} \mathrm{C}$ and humidity of $67-87 \%$ are favorable for the survival of the mycelial form of the fungus. Rainfall and or humidity can cause maceration of the skin which can easily be traumatized and allow entrance of the fungus into the body of horses (18). Here a higher humidity but a lower rainfall was associated with an increased risk of epizootic lymphangitis. A finer analysis would be necessary to disentangle the combined effects of rainfall, humidity, and temperature and to determine whether higher rainfall in areas having higher temperatures leads to increased humidity, which in turn could stress the animals and predispose them to infections. Previous studies revealed that the occurrence of epizootic lymphangitis is common in areas characterized by warm and humid conditions with altitude ranging from 1,500 to $2,300 \mathrm{~m}$ above sea level $(2,7,19)$. In addition, climatic factors such as rainfall also have effects on the skin of horses. Higher rainfall in areas having higher temperature also increases humidity, which stress the animals and predispose them to infections including Histoplasma capsulatum variety farciminosum.

The majority $(87.18 \%)$ of epizootic lymphangitis cases observed were cutaneous forms followed by ocular and pulmonary forms, which is in agreement with the findings of Ameni et al. (7) and Asfaw et al. (17). The frequent occurrence of the lesions over the limbs, neck, and the chest area could be due the direct exposure of the skin over these areas to the effects of harnesses, which causes trauma that favors the entrance of the Histoplasma capsulatum variety farciminosum into the tissues. In addition, the lateral aspects of the body of horses and the limbs are often exposed to chaffing and nails and harnesses that have rigid and rough edges, which create wounds on the skin. The anatomical distribution of epizootic lymphangitis lesions observed in this study are in agreement with the previous reports in horses and mules $(2,7,17)$.

In conclusion, this study revealed the widespread occurrence of epizootic lymphangitis in carthorses in 16 of the 17 towns included in this study ranging from $0.00 \%$ at Debre Birhan to $33.33 \%$ at Kombolcha with an overall prevalence of $16.67 \%$. Statistically significant difference was observed in the prevalence of epizootic lymphangitis and the localities. Climatic factors such as temperature, rainfall, and humidity are important risk factors affecting its occurrence in carthorses in the study towns. The veterinary and livestock authorities should take this into account and devise control strategies to minimize the impacts of the disease and its spread.

\section{DATA AVAILABILITY STATEMENT}

The original contributions presented in the study are included in the article/supplementary material, further inquiries can be directed to the corresponding author.

\section{ETHICS STATEMENT}

The animal study was reviewed and approved by Institutional Review Board of Aklilu Lemma Institute of Pathobiology, Addis Ababa University.

\section{AUTHOR CONTRIBUTIONS}

MA, ST, AZ, and HJ: participated in the collection of field data. GA and ST: developed the proposal and solicited fund. ST, MA, and MG: drafted the paper. GA, BG, MG, and HJ: edited the drafted paper. MA, MG, and AZ: performed laboratory analysis. BG: provided laboratory reagents. All authors contributed to the article and approved the submitted version.

\section{FUNDING}

This work was supported by small amount of grant provided by the Addis Ababa University through its sixth Thematic Research Fund (2017/2018 academic year). We declare that the funding body did not contribute to the execution of any part of the study, interpretation of the results, and write up of this article.

\section{ACKNOWLEDGMENTS}

The authors are grateful to Aklilu Lemma Institute of Pathobiology, Addis Ababa University, for providing part of the necessary materials required for the study, and financial support. The owners of carthorses and associations are also acknowledged for their unreserved collaboration. 


\section{REFERENCES}

1. Bazezew M, Chanie M, Tesfaye T, Kassa A, Mekonnen B, Wagaw N. Lameness and associated risk factors in cart mules in northwestern Ethiopia. Glob Vet. (2014) 12:869-77.

2. Ameni G, Terefe W. A cross-sectional study of epizootic lymphangitis in cart-mules in western Ethiopia. Prev Vet Med. (2004) 66:93-9. doi: $10.1016 /$ j.prevetmed.2004.09.008

3. Teixeira MM, Patané JSL, Taylor ML, Gómez BL, Theodoro RC, Hoog D. Worldwide phylogenetic distributions and population dynamics of the genus histoplasma. PLoS Negl Trop Dis. (2016) 10:e0004732. doi: 10.1371/journal.pntd.0004732

4. World Organization for Animal Health. "Epizootic lymphangitis: Manual of Standards for Diagnostic Test and Vaccines," In: Chapter 3, 5.4, (OIE), Paris, France, (2018) 127-1277. Available online at: http://w.w.w.oie.int/fileadmin/ home/eng/health_standards/tahm/3.5.4_epiz_lymphangitis.

5. Scantlebury C, Reed K. “Epizootic Lymphangitis," In: Mair, T.S., Hutchinson, R.E. editors, Infectious Diseases of the Horse Published by EVJ. Available online at: https://www.researchgate.net/publication/257943301.

6. Agricultural Sample Survey CSA. "2016/17, Volume II: Report on Livestock and livestock characteristics (Private peasant holdings)," In: Statistical Bulletin 585. Central Statistical Agency (CSA). Addis Ababa, Ethopia: Federal Democratic Republic of Ethiopia (2017).

7. Ameni G. Epidemiology of equine histoplasmosis (epizootic lymphangitis) in carthorses in Ethiopia. Vet J. (2005) 172:60-165. doi: $10.1016 /$ j.tvjl.2005.02.025

8. Rovid SA. "Epizootic Lymphangitis," In: The Center for Food Security and Public Health. (2019). Available online at: http://www.cfsph.iastate.edu/ DiseaseInfo/factsheets.php.

9. Ameni G, Siyoum F. Study on Histoplasmosis (epizootic lymphangitis) in cart-horses in Ethiopia. J Vet Sci. (2002) 3:135-40. doi: 10.4142 /jvs.2002.3.2.135

10. Mideksa $\mathrm{K}$, Tesfaye $\mathrm{R}$, Tassew A. Isolation of histoplasma capsulatum var farciminosum and other co-infecting bacteria from local breeds of horses with characteristic lesion of epizootic lymphangutis in Akaki and Kality Districts, Central Ethiopia. ARC J Anim Vet Sci. (2019) 5:15-23. Prefix 10.20431. doi: 10.20431/2455-2518.0501003

11. Umesha S, Manukumar HM, Raghava SA. Rapid method for isolation of genomic DNA from food-borne fungal pathogens. Biotechnol. (2016) 6:1-9. doi: 10.1007/s13205-016-0436-4

12. Jiang B, Bartlett MS, Allen SD, Smith JW, Wheat LJ, Connolly PA, et al. Typing of Histoplasma capsulatum isolates based on nucleotide sequence variation in the internal transcribed spacer regions of rRNA Genes. J Clin Microbiol. (2000) 38:241-5. doi: 10.1128/JCM.38.1.241-245.2000
13. Scantlebury CE, Pinchbeck GL, Loughnane P, Aklilu N, Ashine T, Stringer AP. Development and evaluation of a molecular diagnostic method to rapidly detect Histoplasma capsulatum var. farciminosum (causing Epizootic Lymphangitis) in equine clinical samples. J Equine Vet Sci. (2016) 54:2990-9. doi: 10.1016/j.jevs.2016.02.020

14. Hadush B, Michaelay M, Taddele HM, Abebe N, Tesfaye AG, Kiros HB, et al. Epidemiology of epizootic lymphangitis of carthorses in northern Ethiopia using conventional diagnostic methods and nested polymerase chain reaction. BMC Vet Res. (2020) 16:375. doi: 10.1186/s12917-020-02582-2

15. Wilson RTAR. R of 130 years of equine disease in Sudan. research and reviews. J Vet Sci S1. (2017) 9-22.

16. Abdullahi AS, Abdullahi US, Bale JOO, Sackey AKB, Musa GA, Babashani M. Detection and clinical manifestation of Epizootic Lymphangitis in horses in Zaria and Kontagora Emirates, Nigeria. Savannah Vet J. (2019) 2:1-6. doi: 10.36759/svj.2018.029

17. Asfaw R, Pal M, Ameni G. Prevalence of epizootic lymphangitis in cart horses in Southwest Shewa of Oromia Region, Ethiopia. Int J Livest Res. (2012) 2:146-51. doi: 10.5455/ijlr.20121014122526

18. Londoño LFG, Le'on LCP, Ochoa JGM, Rodriguez AZ, Jaramillo CAP, Ruiz JMA, et al. Capacity of Histoplasma capsulatum to Survive the Composting Process. Review article. Appl Environ Soil Sci. (2019) 19:153. doi: 10.1155./2019/5038153

19. Endebu B, Roger F. Comparative studies on the occurrence and distribution of Epizootic lymphangitis and Ulcerative Lymphangitis in Ethiopia. Int J Appl Res Vet Med. (2016) 1:3.

Conflict of Interest: The authors declare that the research was conducted in the absence of any commercial or financial relationships that could be construed as a potential conflict of interest.

Publisher's Note: All claims expressed in this article are solely those of the authors and do not necessarily represent those of their affiliated organizations, or those of the publisher, the editors and the reviewers. Any product that may be evaluated in this article, or claim that may be made by its manufacturer, is not guaranteed or endorsed by the publisher.

Copyright (c) 2021 Abdela, Teshale, Gobena, Zewde, Jaleta, Gumi and Ameni. This is an open-access article distributed under the terms of the Creative Commons Attribution License (CC BY). The use, distribution or reproduction in other forums is permitted, provided the original author(s) and the copyright owner(s) are credited and that the original publication in this journal is cited, in accordance with accepted academic practice. No use, distribution or reproduction is permitted which does not comply with these terms. 